\title{
Assessment of the accuracy of estimation of gestational age in cattle from placentome size using inverse regression
}

\author{
KE Lawrence*, FD Adeyinka*, RA Laven ${ }^{* \S}$ and G Jones $^{\dagger}$
}

\footnotetext{
* Institute of Veterinary, Animal and Biomedical Sciences, Massey University, Private Bag 11 222, Palmerston North 4442, New Zealand

† Institute of Fundamental Sciences, Massey University, Tennent Drive, Palmerston North 4474, New Zealand

$\checkmark$ Author for correspondence. Email: r.laven@massey.ac.nz
}

Supplementary Figure 1. Graphs showing the relationship between log placentome length and gestational age for nine pregnant dairy cows, with regression lines from a simple regression model (solid line) and a mixed effects model (dashed line).

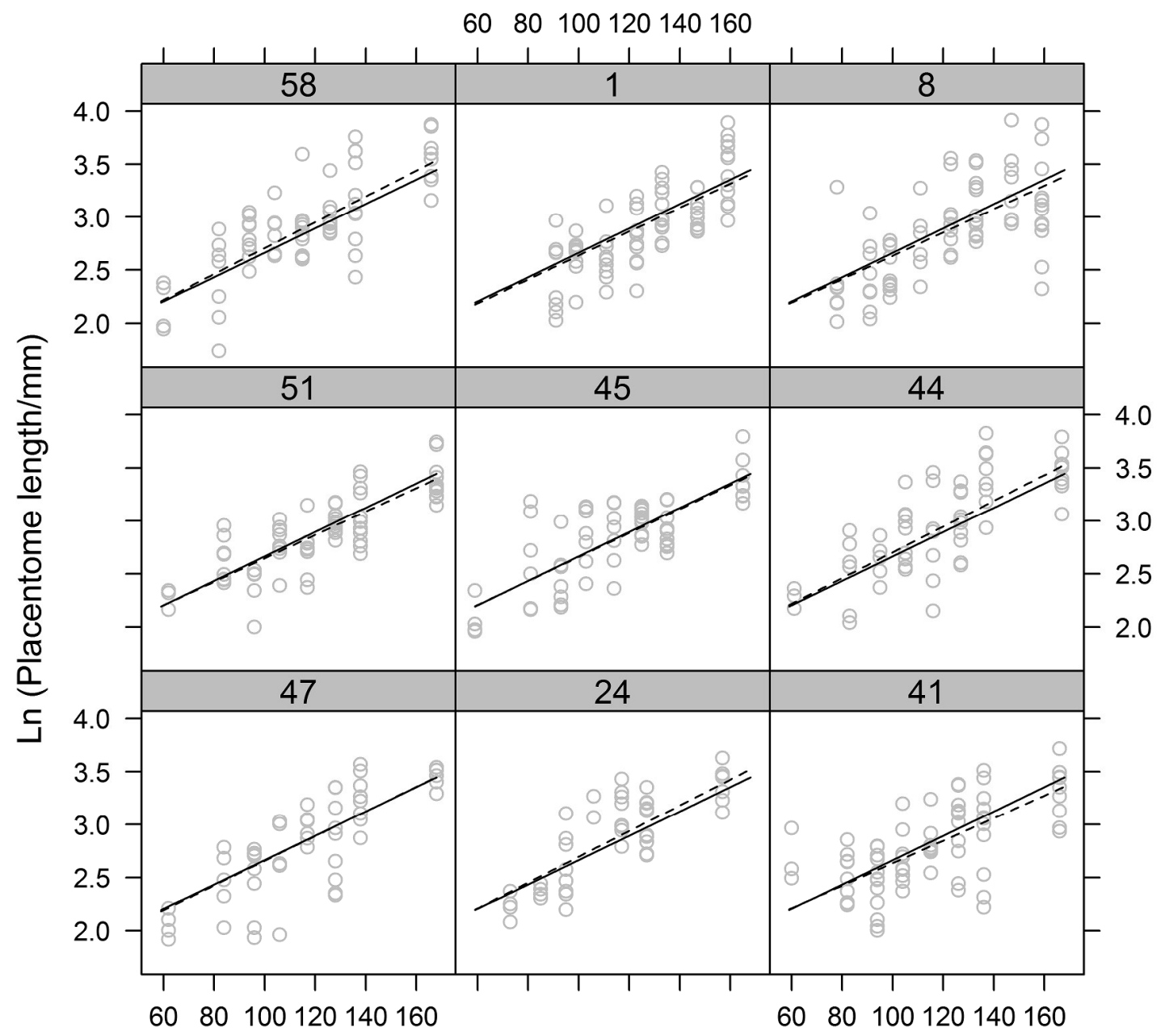

Days Pregnant 